Norden i tal 2012

ANP 2012:751 


\section{Norden i tal 2012}

ISBN 978-92-893-2413-7

ISSN 0908-4339

http://dx.doi.org/10.6027/ANP2012-751

ANP 2012:751

(C) Nordiska ministerrådet 2012

Omslag: Jette Koefoed, Nordiska ministerrådet

Tryck: Rosendahls-Schultz Grafisk, Albertslund

Upplaga: 6000

Printed in Denmark

Huvudsakliga uppgiftslämnare: De nationella statistiska instituten i de nordiska länderna.

Red: Klaus Munch Haagensen, Danmarks Statistik.

Databas: Troels A. Vestergaard, Danmarks Statistik.

\section{Nordiska ministerrådet}

Ved Stranden 18

DK-1061 Köpenhamn K

Telefon: +4533960200

www.norden.org

\section{Det nordiska samarbetet}

Det nordiska samarbetet är ett av världens mest omfattande regionala samarbeten. Det omfattar Danmark, Finland, Island, Norge och Sverige samt Färöarna, Grönland och Åland.

Det nordiska samarbetet är politiskt, ekonomiskt och kulturellt förankrat och är en viktig partner i europeiskt och internationellt samarbete. Den nordiska gemenskapen arbetar för ett starkt Norden i ett starkt Europa.

Det nordiska samarbetet vill styrka nordiska och regionala intressen och värderingar i en global omvärld. Gemensamma värderingar länderna emellan bidrar till att stärka Nordens ställning som en av världens mest innovativa och konkurrenskraftiga regioner. 


\section{Innehåll}

De nordiska länderna

$$
4
$$

Arbetsmarknad

Nyckeltal

Geografi och klimat

8

Kultur

Miljö och energi

9

Ekonomi

Befolkning

Hälsa

Sociala tjänster Utbildning

Symbolen $\square$ under en tabell eller ett diagram markerar en hänvisning till den tabell som utgör källan i databasen Nordic Statistics på www.norden.org. Hänvisningen efter symbolen länkar till den aktuella tabellen i databasen. Med ett klick på referensen kommer du direkt till den rätta tabellen.

Följande symboler och landskoder används genomgående i boken:

\section{Symboler}

Noll

Mindre än hälften $\quad 0$

Inte tillämpligt

Uppgift saknas

\section{Landskoder}

Danmark: DK

Färöarna: FO

Grönland: GL

Finland: FI
Åland: AX

Island: IS

Norge: NO

Sverige: SE

Följande färger används för att beskriva de olika länderna i diagrammen:

Danmark:

Färöarna:
Grönland:

Finland:
Åland:

Island:
Norge:

Sverige: 


\section{De nordiska länderna}
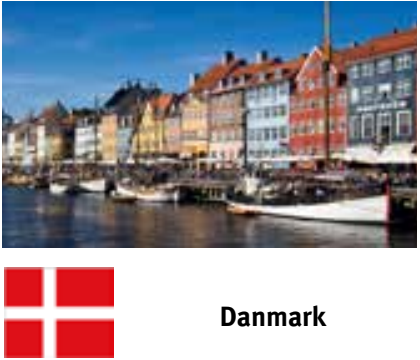

Areal $\mathrm{km}^{2}$

Befolkning

Statsskick/Status Konstitutionell monarki

Statsöverhuvud Drottning Margrethe II

Köpenhamn

1213822
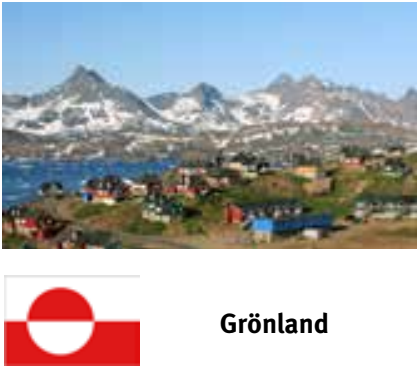

Grönland

Areal km²

2166086

Befolkning

56749

Statsskick/Status

Självstyre, del av

Kungariket Danmark

Statsöverhuvud

Drottning

Margrethe II

Nuuk
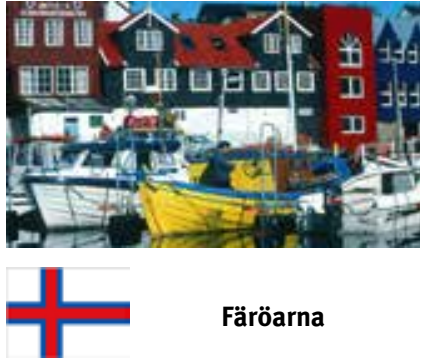

Färöarna

Areal km²

1396

Befolkning

48351

Statsskick/Status

Självstyre, del av Kungariket

Danmark

Statsöverhuvud Drottning Margrethe II

Tórshavn 19834
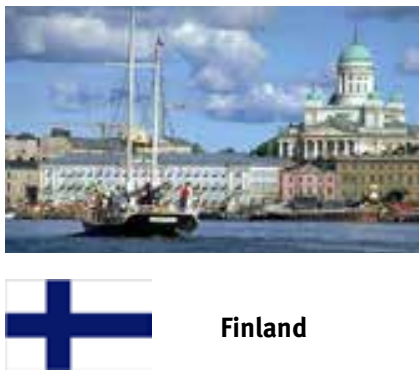

\section{Finland}

Areal $\mathrm{km}^{2}$

338432

Befolkning

5401267

Statsskick/Status Republik

Statsöverhuvud

President

Sauli Niinistö

Helsingfors

1059631 

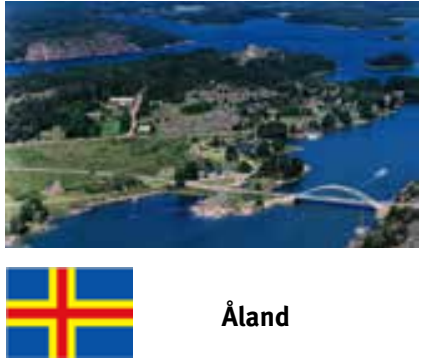

Areal km²

Befolkning

Statsskick/Status

Statsöverhuvud

Mariehamn
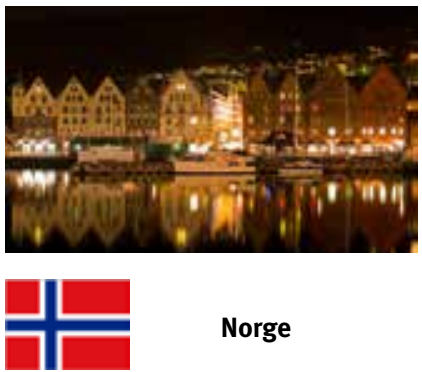

Areal $\mathrm{km}^{2}$

Befolkning

Statsskick/Status

Statsöverhuvud

Oslo
Åland

1580

28355

Självstyre, del av republiken Finland

President

Sauli Niinistö

11263

Norge

323787

4985870

Konstitutionell monarki

Kung Harald V

1169539
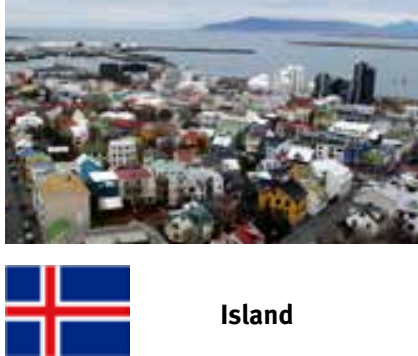

Island

Areal km²

103440

Befolkning

319575

Statsskick/Status Republik

Statsöverhuvud

President

Ólafur Ragnar

Grímsson

Reykjavik

203594
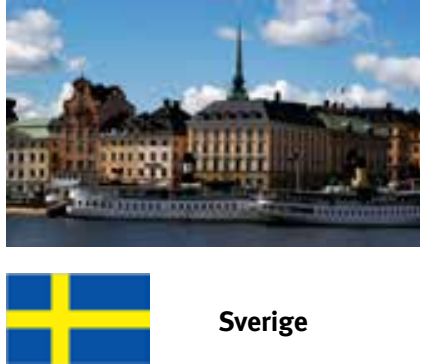

Sverige

Areal $\mathrm{km}^{2}$

450295

Befolkning

9482855

Statsskick/Status

Konstitutionell monarki

Statsöverhuvud Kung Karl XVI Gustav

Stockholm 
Nyckeltal

Norden i ett internationellt sammanhang - nyckeltal $2011^{1}$

Norden Euro- USA Japan

området

Landareal, $1000 \mathrm{~km}^{2}$

Totalt

Isfri

3429

2628

9827

378

Folkmängd

Totalt, miljoner

Invånare per km²

1606

2552

9162

364

Fertilitet

Antal barn per kvinna

26

333

$16 \quad 130$

128

130

314

350

Andel invånare

0-14 år

65+ år

1,9

1,6

2,1

1,3

$17,3 \quad 15,4 \quad 20,1 \quad 13,3$

17,4

18,3

13,1

22,7

Medellivslängd, antal år

\begin{tabular}{lllll}
\hline Män & 78,5 & 78,0 & 76,2 & 79,6 \\
Kvinnor & 83,1 & 83,7 & 81,1 & 86,4
\end{tabular}

$B N P$

Miljarder euro

1088

9413

10830

4220

Per person, euro (PPP)

34400

27100

37100

27000

offentliga sektorn, procent av BNP

Skulder, i slutet av 2009

45,0

85,1

61,3

183,5

Överskott

0,4

$-6,0$

$-10,7$

$-8,7$

Samtliga skatter 2008

44,9

38,9

24,0

28,1

Arbetskraft, procent

Relativa arbetskraftstal

Män

$\begin{array}{rr}81,6 & 79,1 \\ 76,4 & 66,5 \\ 6,7 & 10,1\end{array}$

78,9

84,5

Kvinnor

Arbetslöshet

$6,7 \quad 10,1$

67,8

63,0

${ }^{1} 2011$ eller senast tillgängliga siffror. Norden: Danmark, Finland, Island, Norge, Sverige, Färöarna, Grönland och Åland. Euroområdet (även kallad EA-17)=De 17 europeiska länderna som har infört euron som gemensam valuta. 


\section{Areal (isfri)}

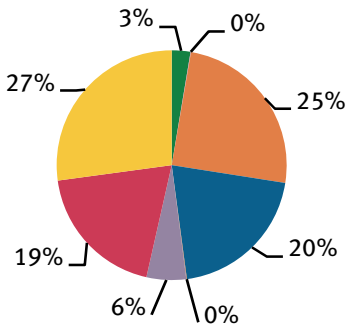

- Danmark 3\%

- Färöarna < $0 \%$

- Grönland 25\%

- Finland $20 \%$

- Åland < $0 \%$

- Island 6\%

norge $19 \%$

Sverige $27 \%$

믈

\section{Folkmängd}

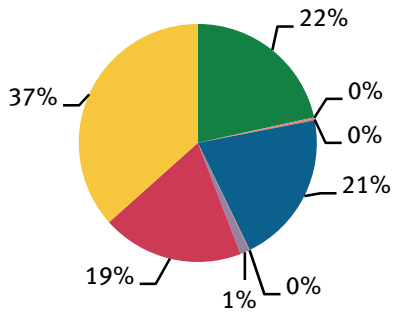

- Danmark 22\%

- Färöarna < $0 \%$

- Grönland < $0 \%$

- Finland 21\%

- Åland < $0 \%$

- Island 1\%

- Norge 19\%

Sverige $37 \%$

Popu01

\section{Bruttonationalinkomst}

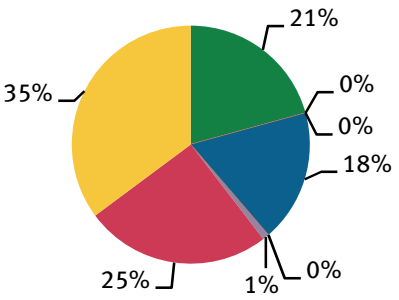

- Danmark 21\%

- Färöarna < $0 \%$

- Grönland < $0 \%$

- Finland $18 \%$

- Åland < $0 \%$

- Island 1\%

- Norge 25\%

Sverige $35 \%$ 
Geografi och klimat

\section{Markanvändning 2011}

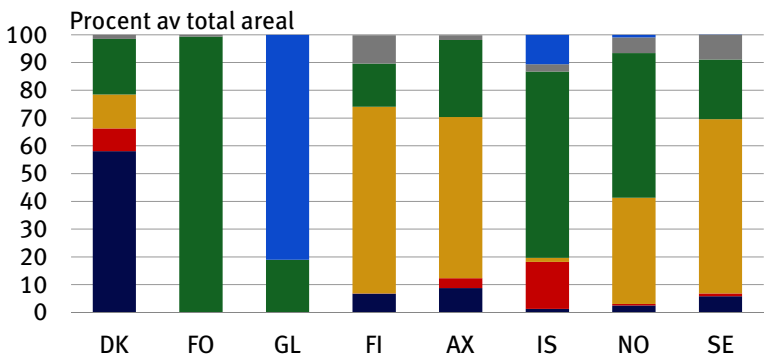
— Åkermark och trädgårdar
- Ängsmark och betesmark
Skog
- Övrig landareal
- Sjöar
- Glaciärer

口Area02

\section{Medeltemperatur i de nordiska huvudstäderna}

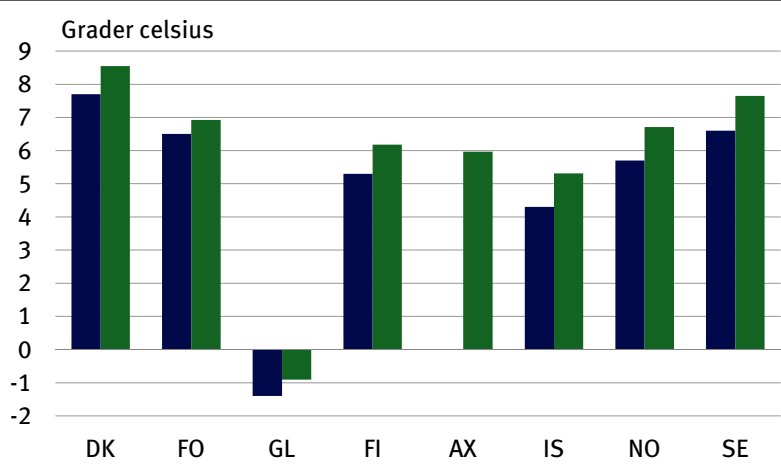

- Medeltemperatur 1961-1990 \# Medeltemperatur 1990-2011 
Utsläpp av växthusgaser per person

\begin{tabular}{lrrrrr}
\hline & DK & FI & IS & NO & SE \\
\hline CO-ekvivalenter, ton & & & & & \\
\hline 1990 & 13,6 & 14,1 & 13,7 & 11,7 & 8,5 \\
1995 & 14,8 & 13,8 & 12,2 & 11,4 & 8,4 \\
2000 & 13,0 & 13,4 & 13,7 & 11,9 & 7,8 \\
2005 & 12,0 & 13,1 & 12,9 & 11,6 & 7,5 \\
2010 & 11,3 & 13,9 & 14,3 & 11,0 & 7,1 \\
\hline
\end{tabular}

Emis11 och Popu02

Energiproduktion, ekvivalenta oljeton 2010

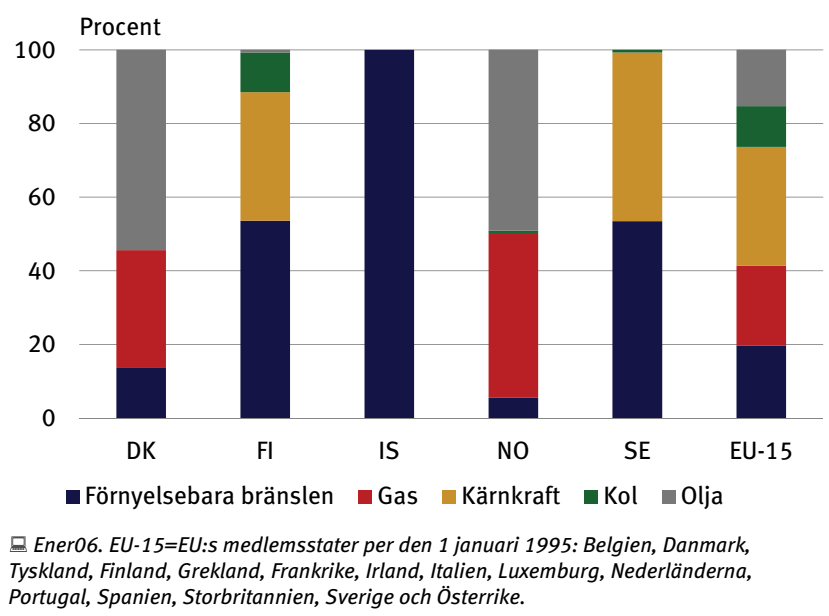


Befolkning

Folkmängd i Norden, 1 januari 2012

\begin{tabular}{lrrr}
\hline & Totalt & Män & Kvinnor \\
\hline Norden totalt & $\mathbf{2 5 8 7 5 \mathbf { 1 8 3 }}$ & $\mathbf{1 2 8 6 0 5 3 4}$ & $\mathbf{1 3 0 1 4 6 4 9}$ \\
Danmark & 5580516 & 2766776 & 2813740 \\
Färöarna & 48351 & 25114 & 23237 \\
Grönland & 56749 & 30041 & 26708 \\
Finland & 5401267 & 2652534 & 2748733 \\
Åland & 28355 & 14136 & 14219 \\
Island & 319575 & 160364 & 159211 \\
Norge & 4985870 & 2498871 & 2486999 \\
Sverige & 9482855 & 4726834 & 4756021 \\
\hline
\end{tabular}

ㅁ Popu01. Finland inkluderar Åland.

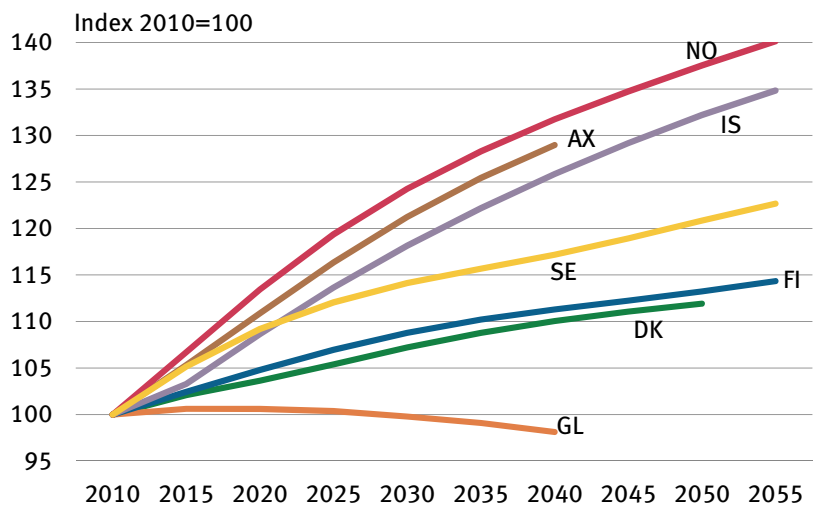




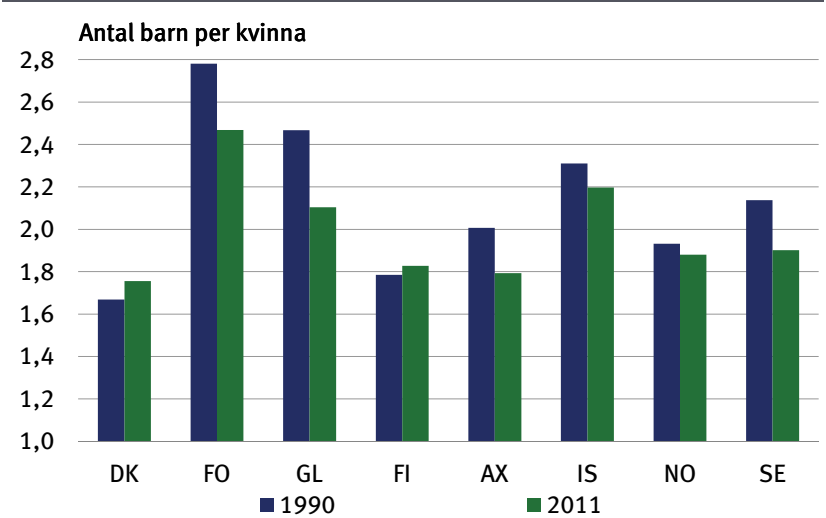

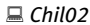

Medellivslängd vid födseln, antal ăr

$\begin{array}{llllllll}\text { DK } & \text { FO } & \text { GL } & \text { FI } & \text { AX } & \text { IS } & \text { NO } & \text { SE }\end{array}$

Män

\begin{tabular}{rrrrrrrrr}
\hline 1990 & 72,0 & 73,1 & 60,7 & 70,9 & 74,7 & 75,0 & 73,4 & 74,8 \\
1995 & 72,6 & 74,5 & 62,3 & 72,8 & 75,1 & 76,5 & 74,8 & 76,2 \\
2000 & 74,3 & 76,2 & 62,8 & 74,1 & 78,5 & 77,6 & 76,0 & 77,4 \\
2005 & 75,6 & 77,2 & 65,5 & 75,5 & 77,6 & 79,2 & 77,7 & 78,4 \\
2010 & 77,1 & 78,7 & 67,9 & 76,7 & 81,2 & 79,5 & 78,9 & 79,5 \\
2011 & 77,3 & 79,1 & 68,3 & 77,2 &.. & 79,9 & 79,0 & 79,8
\end{tabular}

Kvinnor

\begin{tabular}{rrrrrrrrr}
\hline 1990 & 77,7 & 80,3 & 68,4 & 78,9 & 82,8 & 80,1 & 79,8 & 80,4 \\
1995 & 77,8 & 81,3 & 68,3 & 80,2 & 81,1 & 80,6 & 80,8 & 81,5 \\
2000 & 79,0 & 81,6 & 68,0 & 81,0 & 81,5 & 81,4 & 81,4 & 82,0 \\
2005 & 80,2 & 82,2 & 70,9 & 82,3 & 83,6 & 83,1 & 82,5 & 82,8 \\
2010 & 81,2 & 84,4 & 72,9 & 83,2 & 84,2 & 83,5 & 83,2 & 83,5 \\
2011 & 81,6 & 84,9 & 73,0 & 83,5 &.. & 83,6 & 83,5 & 83,7 \\
\hline
\end{tabular}

ㄴife01 


\section{Befolkning}

\section{Asylansökningar}

\begin{tabular}{rrrrrrr} 
& Danmark & Finland & Island & Norge & Sverige & $\begin{array}{r}\text { Norden } \\
\text { totalt }\end{array}$ \\
\hline 1990 & 5292 &.. & 4 & $\ldots$ & 29420 &.. \\
1995 & 5104 &.. & 4 & 1460 & 9047 &. \\
2000 & 10347 & 3170 & 25 & 10843 & 16303 & 40688 \\
2005 & 1283 & 3574 & 87 & 5402 & 17530 & 27876 \\
2006 & 922 & 2324 & 39 & 5320 & 24322 & 32927 \\
2007 & 1029 & 1505 & 42 & 6528 & 36207 & 45311 \\
2008 & 951 & 4035 & 73 & 14431 & 24353 & 43843 \\
2009 & 2022 & 5988 & 34 & 17226 & 24194 & 49464 \\
2010 & 2844 & 4018 & 44 & 10064 & 31819 & 48789 \\
2011 & 3573 & 3087 & 75 & 9053 & 29670 & 45458 \\
\hline
\end{tabular}

D MigrO4

\section{Nettomigration}

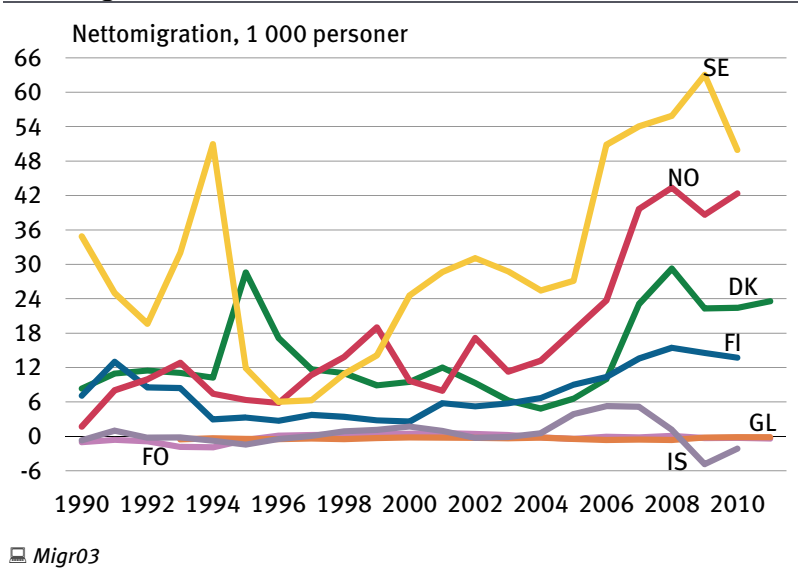


Hälsa

Personer som röker dagligen

\begin{tabular}{lcccccc} 
& DK & FO & FI & IS & NO & SE \\
\hline $\begin{array}{l}\text { Procent } \\
\text { Män }\end{array}$ & & & & & & \\
\hline 1995 & 44 &.. & 29 & 32 & 33 & 22 \\
2000 & 31 &.. & 27 & 23 & 31 & 17 \\
2005 & 28 & 28 & 26 & 20 & 27 & 14 \\
2009 & 24 & 24 & 22 & 15 & 21 & 13 \\
Kvinnor & & & & & & \\
1995 & 39 &.. & 19 & 33 & 32 & 24 \\
2001 & 26 &.. & 20 & 22 & 32 & 21 \\
2005 & 23 & 27 & 18 & 20 & 24 & 18 \\
2009 & 22 & 24 & 14 & 16 & 20 & 15 \\
\hline
\end{tabular}

ㅁ Heal01

Försäljning av alkoholdrycker

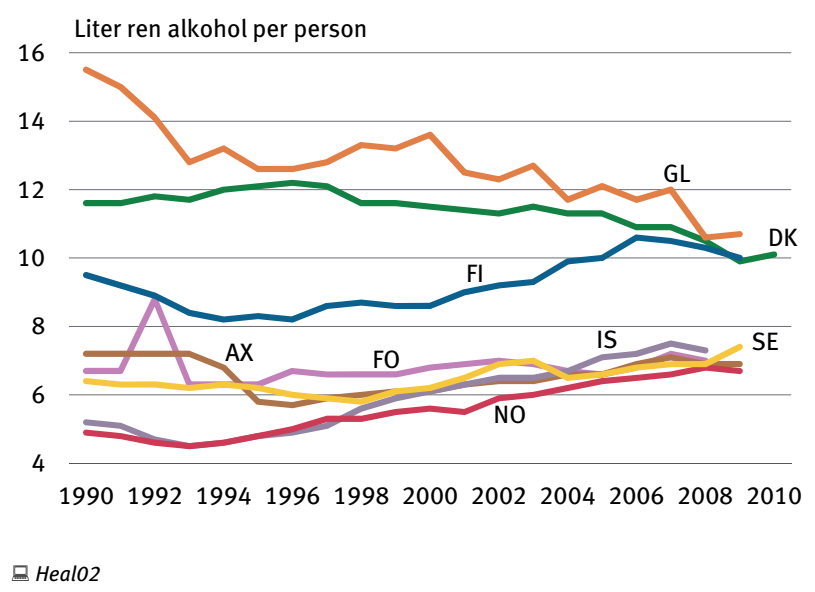


Hälsa

Dödsorsaker per 100000 personer
DK FO
GL
FI $\quad$ AX
IS NO
SE

Män

2005

Cancer

$\begin{array}{llllllll}300 & 206 & 218 & 215 & 310 & 193 & 224 & 256\end{array}$

Hjärt- och

$\begin{array}{lllllllll}\text { kärlsjukdomar } & 303 & 335 & 185 & 364 & 338 & 226 & 300 & 418\end{array}$

$\begin{array}{lllllllll}\text { Självmord } & 17 & 12 & 89 & 28 & 23 & 16 & 16 & 19\end{array}$

Olyckor

$35 \quad 37$

$82 \quad 81$

$43 \quad 26$

$50 \quad 44$

2009

$\begin{array}{lllllllll}\text { Cancer } & 281 & 182 & 208 & 222 & 279 & 192 & 234 & 245\end{array}$

Hjärt- och

$\begin{array}{lllllllll}\text { kärlsjukdomar } & 259 & 261 & 131 & 376 & 332 & 236 & 257 & 374\end{array}$

$\begin{array}{lllllllll}\text { Självmord } & 17 & 8 & 100 & 29 & 12 & 18 & 17 & 19\end{array}$

$\begin{array}{lllllllll}\text { Olyckor } & 28 & 63 & 60 & 74 & 61 & 25 & 45 & 37\end{array}$

Kvinnor

2005

Cancer

$\begin{array}{llllllll}276 & 212 & 225 & 189 & 198 & 152 & 213 & 227\end{array}$

Hjärt- och

$\begin{array}{lllllllll}\text { kärlsjukdomar } & 322 & 334 & 188 & 389 & 455 & 217 & 328 & 436\end{array}$

$\begin{array}{lllllllll}\text { Självmord } & 6 & 1 & 86 & 10 & 5 & 6 & 7 & 8\end{array}$

$\begin{array}{lllllllll}\text { Olyckor } & 27 & 19 & 53 & 36 & 17 & 18 & 34 & 31\end{array}$

2009

$\begin{array}{lllllllll}\text { Cancer } & 259 & 201 & 227 & 191 & 242 & 160 & 203 & 222\end{array}$

Hjärt- och

$\begin{array}{lllllllll}\text { kärlsjukdomar } & 271 & 244 & 136 & 386 & 400 & 221 & 301 & 403\end{array}$

$\begin{array}{lrrrrrrrr}\text { Självmord } & 5 & 1 & 27 & 10 & 13 & 4 & 7 & 8\end{array}$

$\begin{array}{lllllllll}\text { Olyckor } & 23 & 13 & 38 & 33 & 21 & 16 & 35 & 25\end{array}$

Deal03, Heal04, Heal05 och Heal07 
Barn i barnomsorg efter åldersgrupp, 2011

\begin{tabular}{|c|c|c|c|c|c|c|c|}
\hline & DK & FO & FI & $A X$ & IS & NO & SE \\
\hline \multicolumn{8}{|c|}{ Procent av barn i barnomsorg per åldersgrupp } \\
\hline Totalt & 82,7 & 78,5 & 50,0 & 59,6 & 74,6 & 76,2 & 72,0 \\
\hline 0 år & 18,9 & 16,8 & 1,0 & & 6,8 & 4,3 & 0,0 \\
\hline 1 år & 89,4 & 83,5 & 29,8 & 24,9 & 65,9 & 70,6 & 49,3 \\
\hline 2 år & 91,7 & 86,9 & 51,4 & 55,0 & 93,6 & 89,0 & 91,4 \\
\hline 3 år & 97,9 & 92,1 & 68,0 & 78,9 & 95,5 & 96,7 & 96,1 \\
\hline 4 år & 97,2 & 89,3 & 74,0 & 93,4 & 96,7 & 97,3 & 97,7 \\
\hline 5 år & 97,2 & 96,5 & 78,2 & 92,4 & 93,8 & 98,9 & 98,3 \\
\hline
\end{tabular}

口Chil03. Barn i helt eller delvis offentligt finansierad barnomsorg.

\section{Antal dagar med föräldrapenning vid graviditet, 2010}

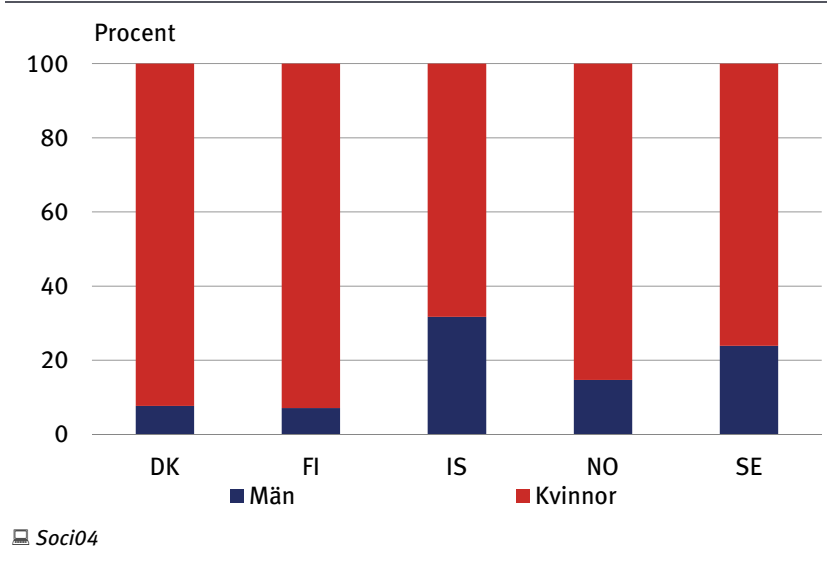


Studerandes prestationer, PISA 2009

\begin{tabular}{|c|c|c|c|c|c|}
\hline \multicolumn{2}{|l|}{ Läsförståelse } & \multicolumn{2}{|c|}{ Kunskaper i matematik } & \multicolumn{2}{|l|}{$\begin{array}{l}\text { Kunskaper i } \\
\text { naturvetenskap }\end{array}$} \\
\hline Sydkorea & 539 & Sydkorea & 546 & Finland & 554 \\
\hline Finland & 536 & Finland & 541 & Japan & 539 \\
\hline Åland & 527 & Åland & 536 & Aland & 539 \\
\hline Kanada & 524 & Schweiz & 534 & Sydkorea & 538 \\
\hline Nya Zeeland & 521 & Japan & 529 & Nya Zeeland & 532 \\
\hline Japan & 520 & Kanada & 527 & Kanada & 529 \\
\hline Australien & 515 & Nederländerna & 526 & Estland & 528 \\
\hline Nederländerna & 508 & Nya Zeeland & 519 & Australien & 527 \\
\hline Belgien & 506 & Belgien & 515 & Nederländerna & 522 \\
\hline Norge & 503 & Australien & 514 & Tyskland & 520 \\
\hline Estland & 501 & Tyskland & 513 & Schweiz & 517 \\
\hline Schweiz & 501 & Estland & 512 & Storbritannien & 514 \\
\hline Polen & 500 & Island & 507 & Slovenien & 512 \\
\hline Island & 500 & Danmark & 503 & Polen & 508 \\
\hline USA & 500 & Slovenien & 501 & Irland & 508 \\
\hline Sverige & 497 & Norge & 498 & Belgien & 507 \\
\hline Tyskland & 497 & Frankrike & 497 & Ungern & 503 \\
\hline Irland & 496 & Slovakien & 497 & USA & 502 \\
\hline Frankrike & 496 & Österrike & 496 & OECD & 501 \\
\hline Danmark & 495 & OECD & 496 & Tjeckien & 500 \\
\hline Storbritannien & 494 & Polen & 495 & Norge & 500 \\
\hline Ungern & 494 & Sverige & 494 & Danmark & 499 \\
\hline OECD & 493 & Tjeckien & 493 & Frankrike & 498 \\
\hline Portugal & 489 & Storbritannien & 492 & Island & 496 \\
\hline Italien & 486 & Ungern & 490 & Sverige & 495 \\
\hline Slovenien & 483 & Luxemburg & 489 & Österrike & 494 \\
\hline Grekland & 483 & USA & 487 & Portugal & 493 \\
\hline Spanien & 481 & Irland & 487 & Slovakien & 490 \\
\hline Tjeckien & 478 & Portugal & 487 & Italien & 489 \\
\hline Slovakien & 477 & Spanien & 483 & Spanien & 488 \\
\hline Israel & 474 & Italien & 483 & Luxemburg & 484 \\
\hline Luxemburg & 472 & Grekland & 466 & Grekland & 470 \\
\hline Österrike & 470 & Färöarna & 448 & Israel & 455 \\
\hline Turkiet & 464 & Israel & 447 & Turkiet & 454 \\
\hline Chile & 449 & Turkiet & 445 & Chile & 447 \\
\hline Färöarna & 436 & Chile & 421 & Färöarna & 431 \\
\hline Mexiko & 425 & Mexiko & 419 & Mexiko & 416 \\
\hline
\end{tabular}


Studenter vid universitet/högskola i åldern 20-39 år

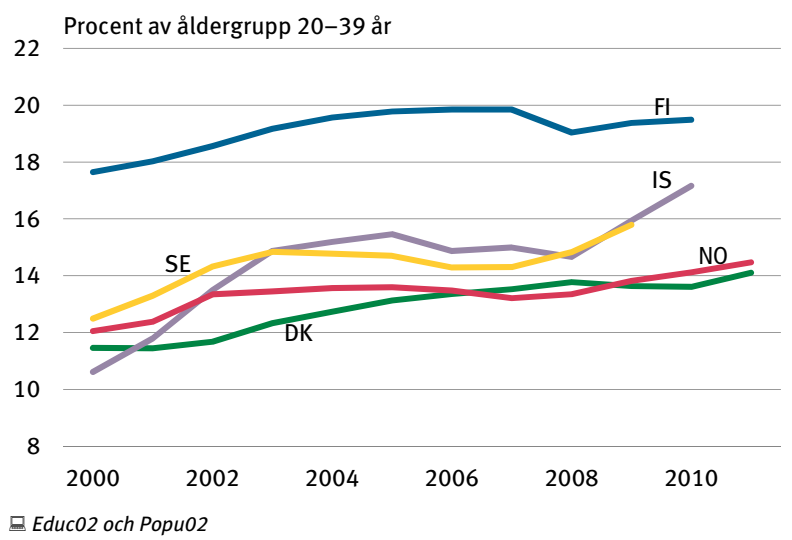

Nordiska studerande $i$ utlandet efter studieland 2010/2011

\begin{tabular}{lrrrrrr}
\hline Personer från & DK & FI & AX & IS & NO & SE \\
\hline Total & $\mathbf{3 3 8 5}$ & $\mathbf{5 4 5 7}$ & $\mathbf{1 0 5 8}$ & $\mathbf{2} \mathbf{4 0 6}$ & $\mathbf{1 5} \mathbf{1 6 9}$ & $\mathbf{2 1 7 0 5}$ \\
\hline Studieland: & & & & & & \\
Norden, totalt & $\mathbf{6 1 4}$ & $\mathbf{1 1 7 8}$ & $\mathbf{1 0 1 5}$ & $\mathbf{1 3 0 7}$ & $\mathbf{4 0 8 7}$ & $\mathbf{3 1 2 1}$ \\
Danmark & $\mathbf{6}$ & 133 & 6 & 1058 & 2938 & 2117 \\
Finland & 16 &. & 228 & 3 & 37 & 215 \\
Island & 46 & 13 & 1 &. & 34 & 26 \\
Norge & 189 & 76 & 6 & 66 &. & 763 \\
Sverige & 363 & 956 & 774 & 180 & 1078 &. \\
Frankrike & 69 & 101 & - & 23 & 322 & 832 \\
Tyskland & 198 & 263 & 2 & 61 & 207 & 656 \\
Storbritannien & 1478 & 1777 & 17 & 247 & 3552 & 4484 \\
USA & 307 & 370 & 8 & 324 & 1264 & 4110 \\
Övriga & 719 & 1768 & 16 & 444 & 5737 & 8502 \\
& & & & & &
\end{tabular}

ㅁduc05 
Relativ arbetskraft efter kön 2011

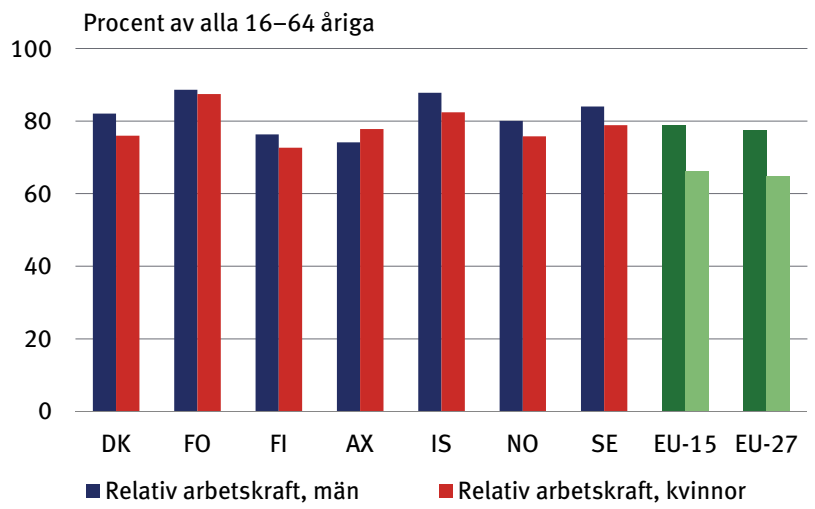

Work02. EU-27=EU-15 + Bulgarien, Cypern, Estland, Lettland, Litauen, Malta, Polen, Rumänien, Slovenien, och Slovakien, Tjeckien och Ungern.

\section{Arbetslöshet}

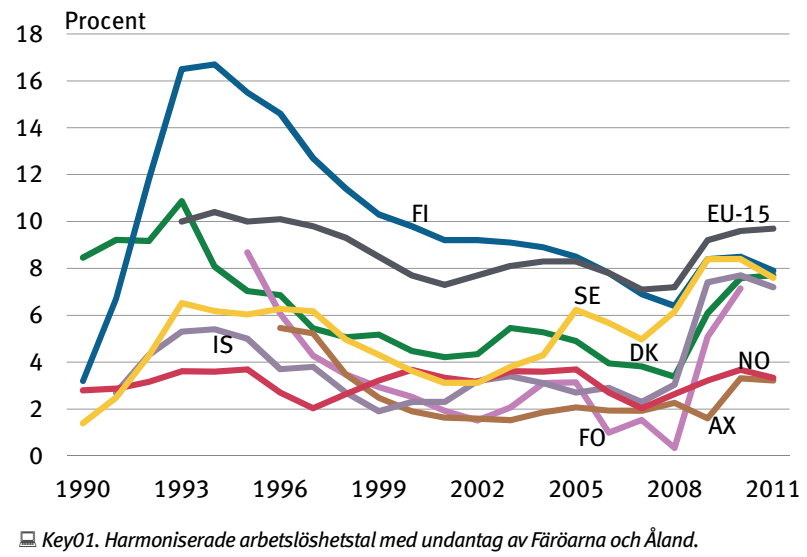


Arbetsmarknad

Arbetslöshet efter åldersgrupp 2011

\begin{tabular}{lrrrrrrr}
\hline & DK & FO & FI & AX & IS & NO & SE \\
\hline Procent av arbetskraften & & & & & & \\
\hline Totalt & $\mathbf{7 , 7}$ & $\mathbf{7 , 1}$ & $\mathbf{7 , 9}$ & $\mathbf{3 , 2}$ & $\mathbf{7 , 2}$ & $\mathbf{3 , 3}$ & $\mathbf{7 , 6}$ \\
16-19 år & 17,2 & 27,3 & 29,6 & 11,8 & 17,4 & 11,5 & 34,2 \\
$20-24$ år & 11,9 & 12,0 & 16,0 & 6,8 & 12,6 & 7,2 & 18,2 \\
25-34 år & 9,7 & 6,7 & 7,5 & 3,2 & 8,6 & 4,0 & 7,2 \\
35-44 år & 5,5 & 3,1 & 5,5 & 1,8 & 4,0 & 2,3 & 4,8 \\
45-54 år & 5,3 & 2,6 & 5,6 & 3,0 & 4,5 & 2,1 & 4,6 \\
55-64 år & 5,7 & 4,8 & 6,4 & 3,1 & 5,4 & 1,2 & 4,7 \\
\hline
\end{tabular}

믄 Work02

Deltidsanställning efter kön 2011

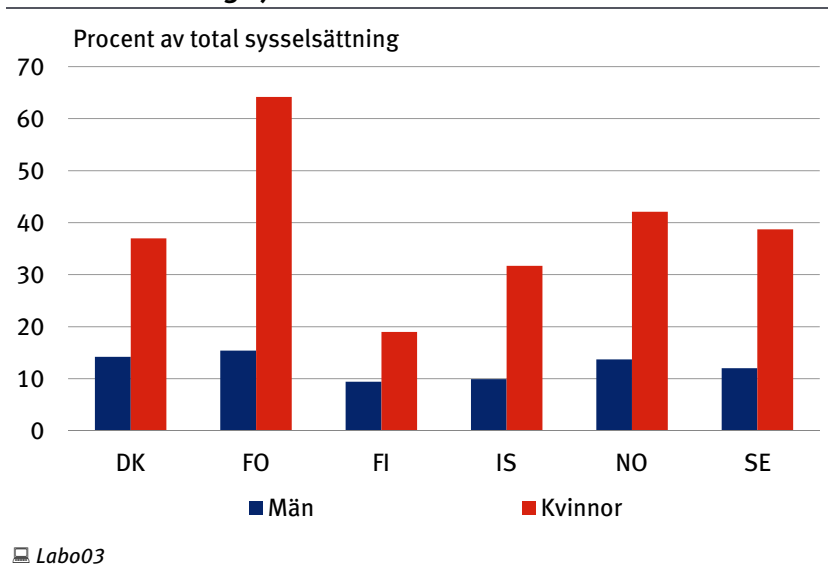


Val

Giltiga röster vid de två senaste nationella valen

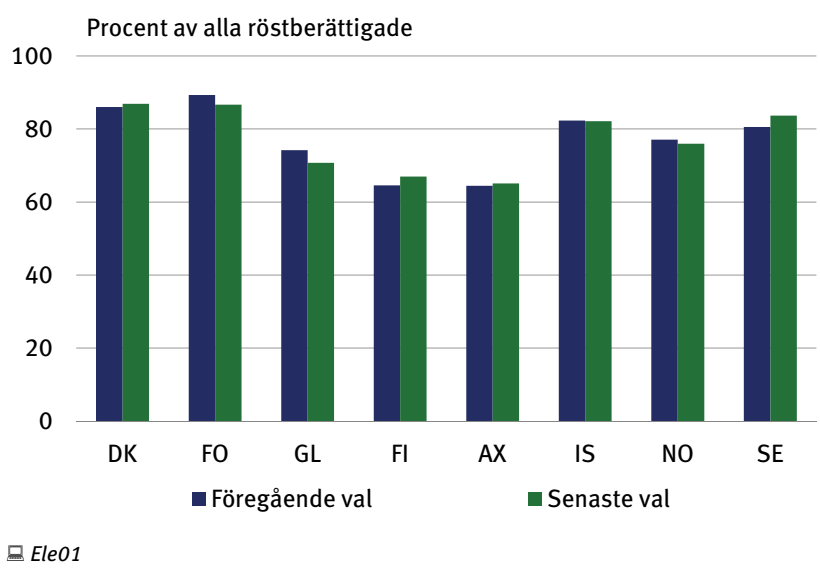

Invalda ledamöter till de nationella parlamenten vid senaste valet

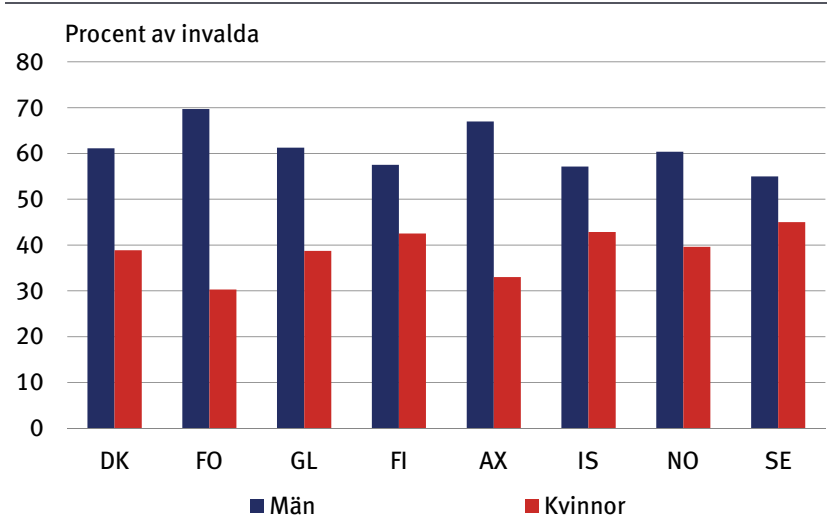

Ele03 
Försäljning av musik 2011

\begin{tabular}{lrrrrr} 
& DK & FI & IS & NO & SE \\
\hline 1 000 euro & & & & & \\
\hline Total försäljning & $\mathbf{5 6 4 5 1}$ & $\mathbf{3 3 1 3 9}$ & $\mathbf{4 2 0 6}$ & $\mathbf{6 4 9 1 1}$ & $\mathbf{9 2 9 8 3}$ \\
Digital försäljning & 22043 & 8174 & 124 & 17883 & 47568 \\
$\begin{array}{l}\text { Procent } \\
\text { Total försäljning }\end{array}$ & 100 & $\mathbf{1 0 0}$ & $\mathbf{1 0 0}$ & $\mathbf{1 0 0}$ & $\mathbf{1 0 0}$ \\
Digital försäljning & 39,1 & 24,7 & 3,0 & 27,6 & 51,2 \\
\hline
\end{tabular}

몬 Cult19

Antal museibesökare 2011

Besök per person

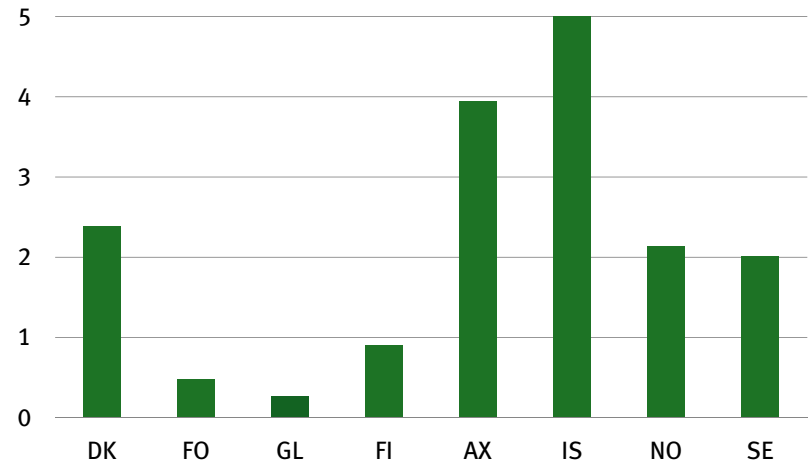

D Cult16 och Popu02 
Ekonomi

Ekonomiska nyckeltal, Norden och euroområdet 2010

DK FI IS NO SE Euroområdet

Procent av BNP

Bytesbalans överskott

$5,6 \quad 3,1 \quad-7,8 \quad 13,7 \quad 6,4 \quad 0,7$

Utländska tillgångar,

netto, 31 dec. 2010

$\begin{array}{lllll}10,0 & 8,9 & -605,8 & 104,4 & -24,2\end{array}$

Offentliga sektorns

överskott

$\begin{array}{llllll}-2,7 & -2,5 & -7,8 & 10,5 & 0,0 & -6,0\end{array}$

Offentliga sektorns

skulder, $31 \mathrm{dec} .2010$

$\begin{array}{llllll}43,6 & 48,4 & 89,5 & 44,7 & 39,8 & 85,1\end{array}$

Procent

Arbetslöshetstal

$7,4 \quad 8,2$

7,7

3,5

$8,4 \quad 10,1$

Ränta

$2,9 \quad 3,0$

5,0

$3,5 \quad 2,9$

3,8

Procentuell förändring

2009-2010

Tillväxt i kon-

sumentpriser

Ekonomisk tillväxt

$2,2 \quad 1,7$

7,5

2,3

1,9

1,6

Aktiekursindex

$1,7 \quad 3,6 \quad-3,5$

0,3

5,7

1,8

Effektivt nominellt

$33,2 \quad 21,5 \quad 21,9 \quad 26,6 \quad 30,5 \quad 13,5$

valutakursindex

$-3,6 \quad-5,7$

$\begin{array}{lll}. & 4,7 & 7,0\end{array}$

Dey01. Harmoniserade arbetslöshetstal. Euroområdet (även kallad EA-17)=De

17 europeiska länderna som har infört euron som gemensam valuta. 
Prisnivå på fastigheter

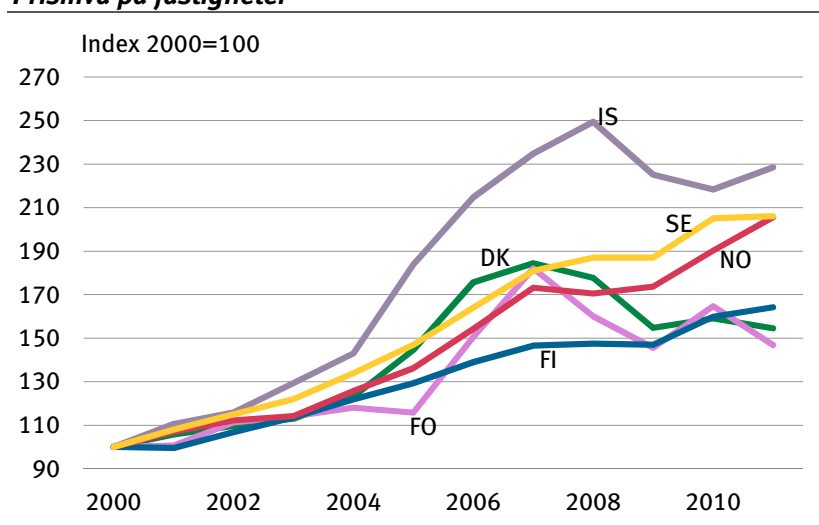

DPric05

\section{Utländska direktinvesteringar}

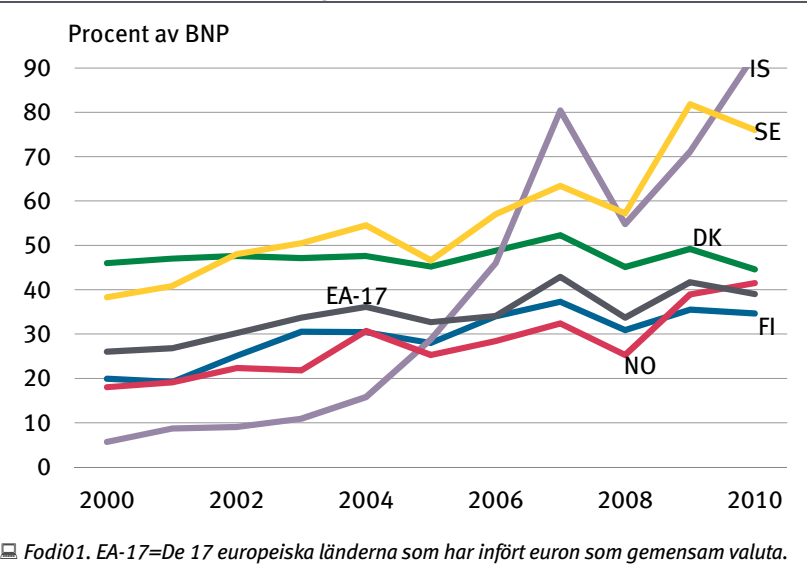


Ekonomi

Bruttonationalprodukten per person i euro (PPP)

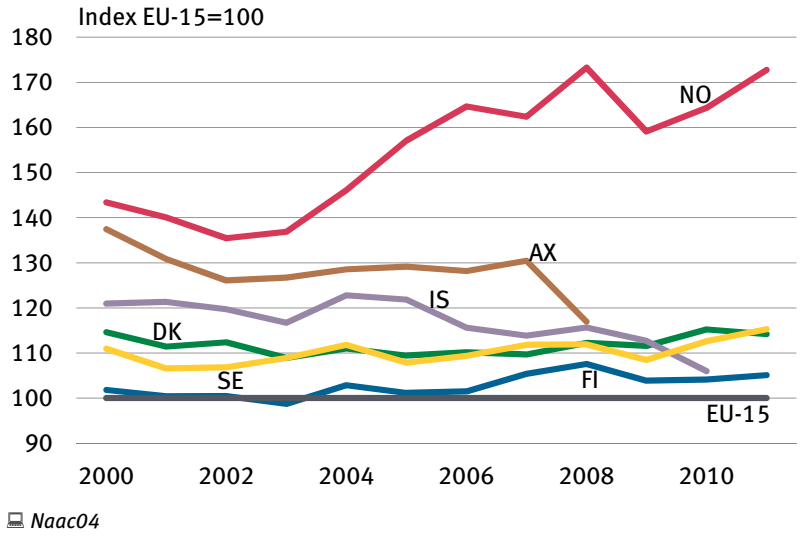

Bruttonationalprodukten, årlig real tillväxt

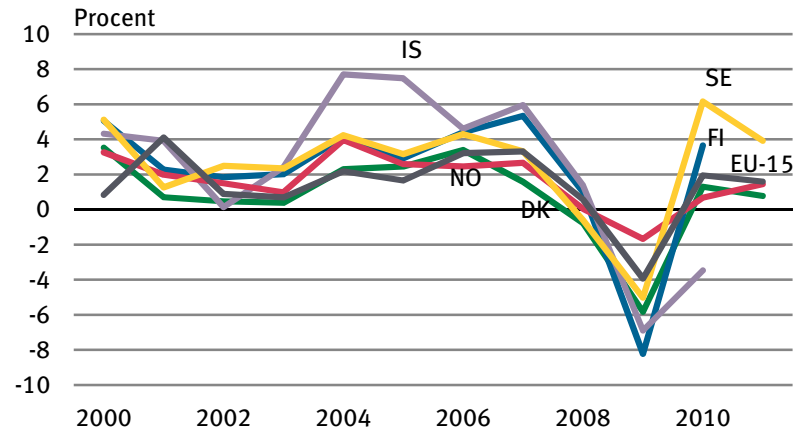

@ Naac01 och Key01 
Nordisk export till och import från vissa länder och regioner 2010

Procent

DK

FI

IS

NO

SE

Export till:

Totalt

Norden

EU-15 (exkl. DK, FI, SE)

De 12 nya EU-länderna

Ryssland

Övriga Europa

USA och Kanada

Övriga Amerika

Japan

DAE-länderna

Kina

Indien

Övriga världen

Import från:

\section{Totalt}

Norden

EU-15 (exkl. DK, Fl, SE)

De 12 nya EU-länderna

Ryssland

Övriga Europa

USA och Kanada

Övriga Amerika

Japan

DAE-länderna

Kina

Indien

Övriga världen

$\begin{array}{rrrrr}\mathbf{1 0 0 , 0} & \mathbf{1 0 0 , 0} & \mathbf{1 0 0 , 0} & \mathbf{1 0 0 , 0} & \mathbf{1 0 0 , 0} \\ 23,1 & 16,2 & 8,5 & 11,8 & 23,0 \\ 44,2 & 34,0 & 71,2 & 66,3 & 38,4 \\ 5,7 & 7,4 & 3,0 & 3,1 & 5,8 \\ 1,7 & 8,9 & 2,1 & 0,9 & 1,8 \\ 2,2 & 3,7 & 2,9 & 1,3 & 2,7 \\ 7,4 & 8,2 & 5,0 & 6,6 & 8,3 \\ 2,4 & 2,5 & 0,4 & 1,2 & 2,5 \\ 1,9 & 1,7 & 2,5 & 1,2 & 1,3 \\ 3,2 & 3,6 & 1,1 & 3,3 & 2,8 \\ 2,4 & 5,2 & 0,6 & 1,7 & 3,1 \\ 0,5 & 1,2 & 0,1 & 0,3 & 1,2 \\ 5,3 & 7,5 & 2,6 & 2,2 & 9,2\end{array}$

$\begin{array}{rrrrr}\mathbf{1 0 0 , 0} & \mathbf{1 0 0 , 0} & \mathbf{1 0 0 , 0} & \mathbf{1 0 0 , 0} & \mathbf{1 0 0 , 0} \\ 21,8 & 19,4 & 27,2 & 23,2 & 22,2 \\ 48,4 & 39,5 & 29,9 & 33,7 & 45,5 \\ 7,1 & 7,2 & 4,4 & 6,8 & 8,0 \\ 1,1 & 17,6 & 0,6 & 2,6 & 4,9 \\ 2,2 & 1,5 & 2,0 & 2,2 & 1,7 \\ 3,4 & 2,7 & 9,6 & 8,7 & 3,5 \\ 2,0 & 2,0 & 13,0 & 2,7 & 1,5 \\ 0,4 & 0,7 & 2,3 & 2,2 & 1,7 \\ 3,3 & 2,1 & 1,8 & 5,7 & 3,3 \\ 7,2 & 4,4 & 6,0 & 8,5 & 5,0 \\ 0,8 & 0,5 & 1,0 & 0,5 & 0,5 \\ 2,4 & 2,4 & 2,0 & 3,3 & 2,2\end{array}$

글 Fotr49. DAE-länderna (dynamiska asiatiska ekonomier)=Hongkong, Malaysia, Singapore, Sydkorea, Taiwan och Thailand. 
Utrikeshandel

Inomnordisk export och import 2010

Procent av total inomnordisk export och import

30

25

20

15

10

5

0

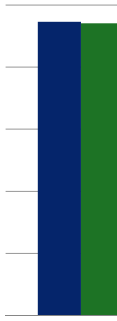

Danmark
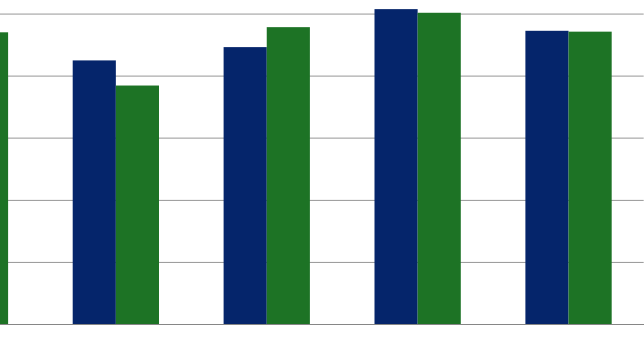

Finland

Island

Norge

Sverige

- Import

- Export

ㅁ Fotr49

\section{Handelsbalans för varor}

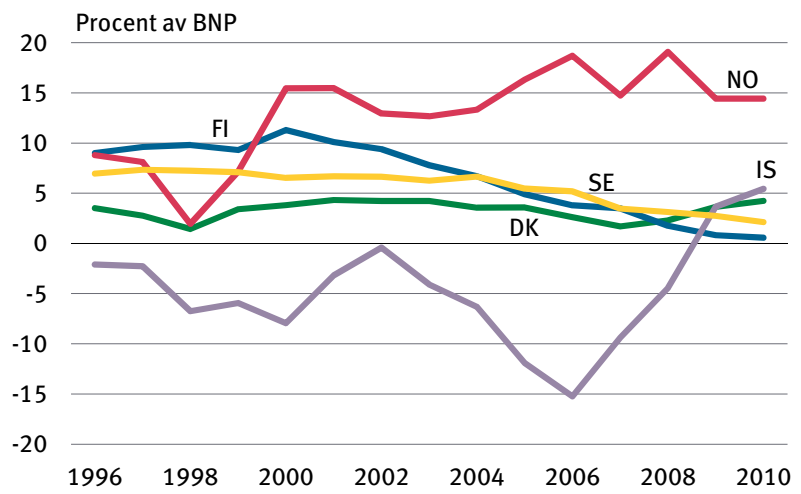

․ Fotr49 och Naac01 
Konsumentprisindex 2011

Index 2005=100

160

150

140

130

120

110

100
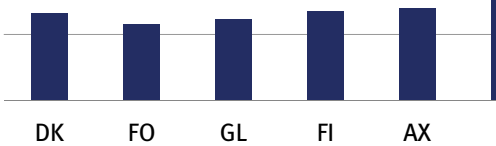

$\mathrm{Fl}$

AX

IS

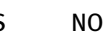

NO SE

[D Pric01. Grönland: 2008 års uppgifter.

Prisnivå 2011

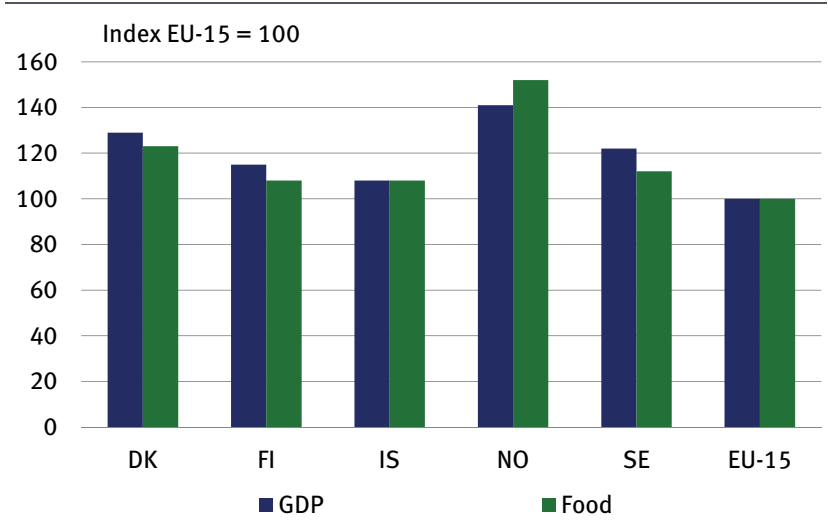

모이 
Offentlig ekonomi och priser

\section{Offentliga utgifter efter ändamål 2009}

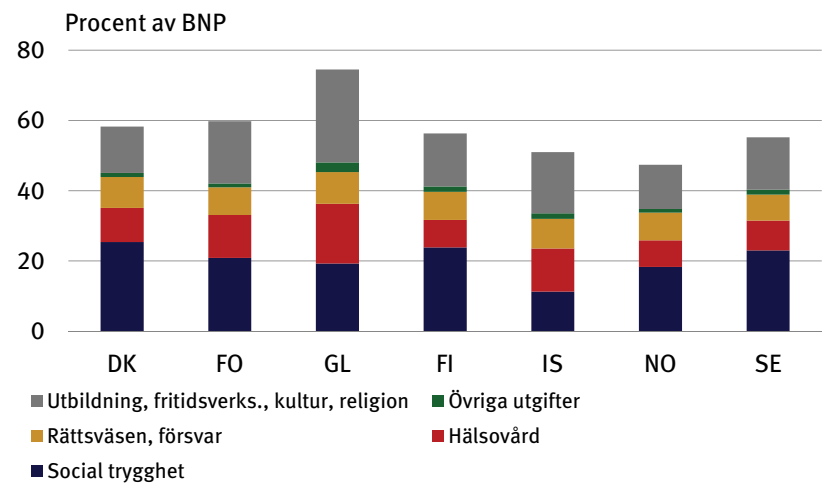

Pubs13. Grönland: 2007 års uppgifter

\section{Offentliga sektorns bruttoskuld}

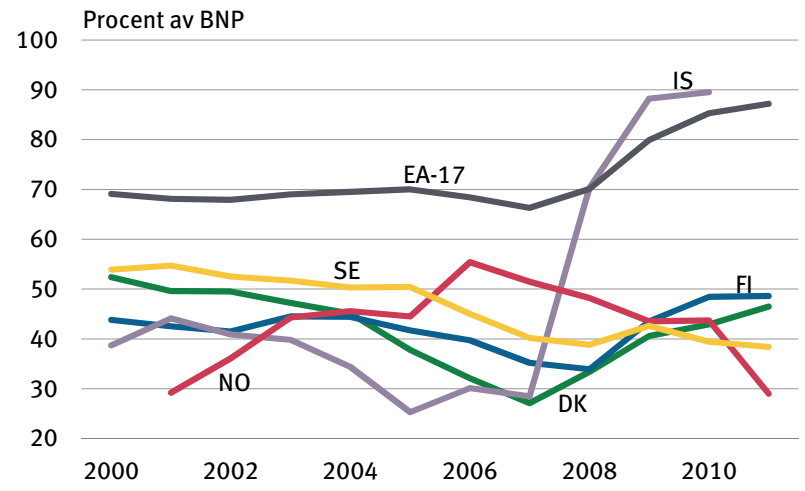




\section{Aktiekurser}

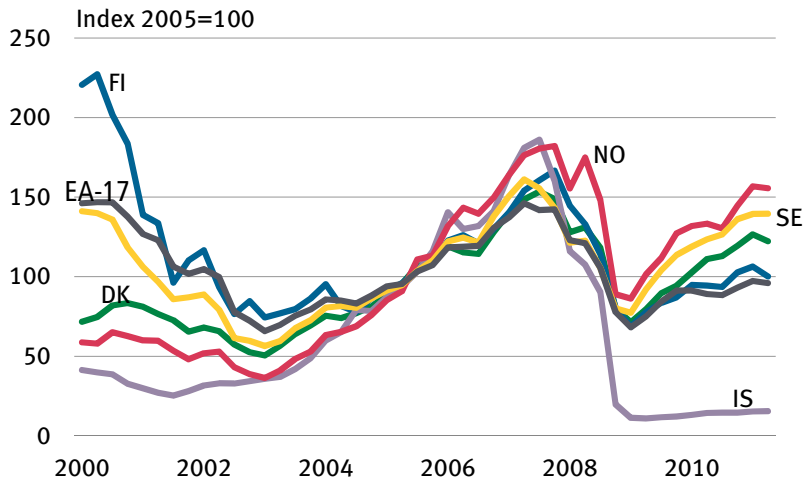

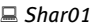

\section{Statligt internationellt bistånd till utvecklingsländerna}

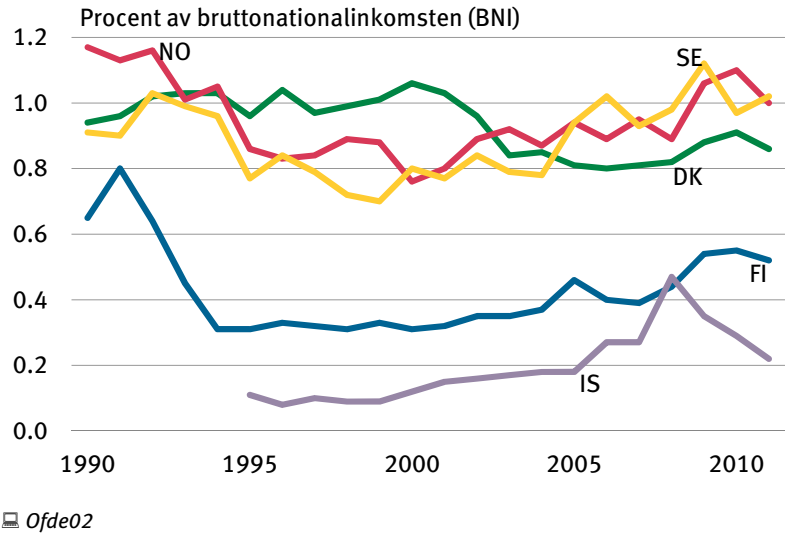


Vetenskap och teknologi

FoU-utgifter per utförande sektor 2010

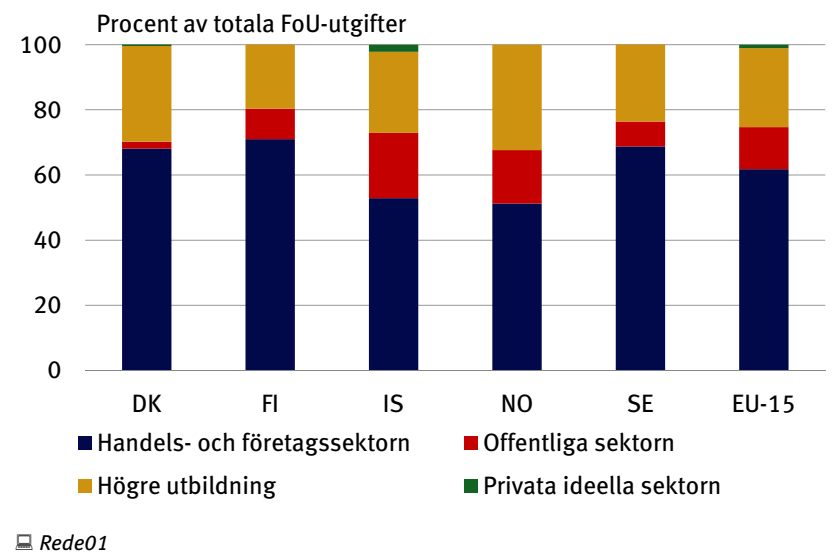

\section{Patent 2011}

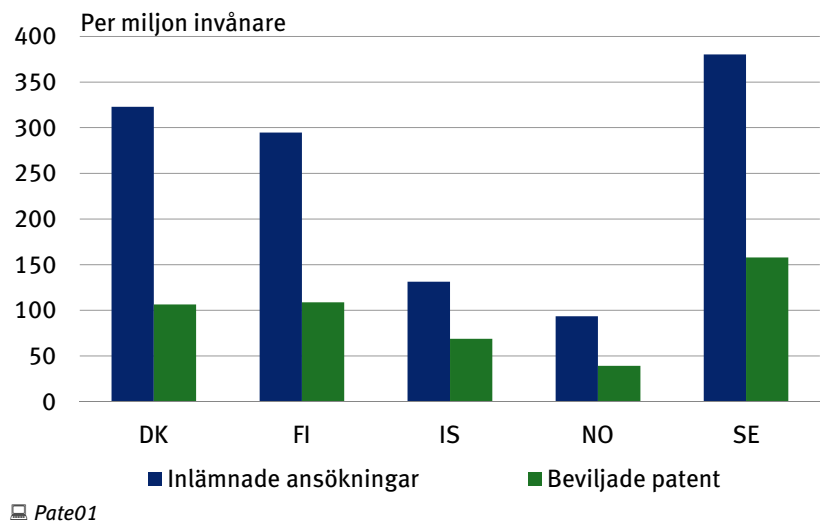


Filosofie doktorer 2010

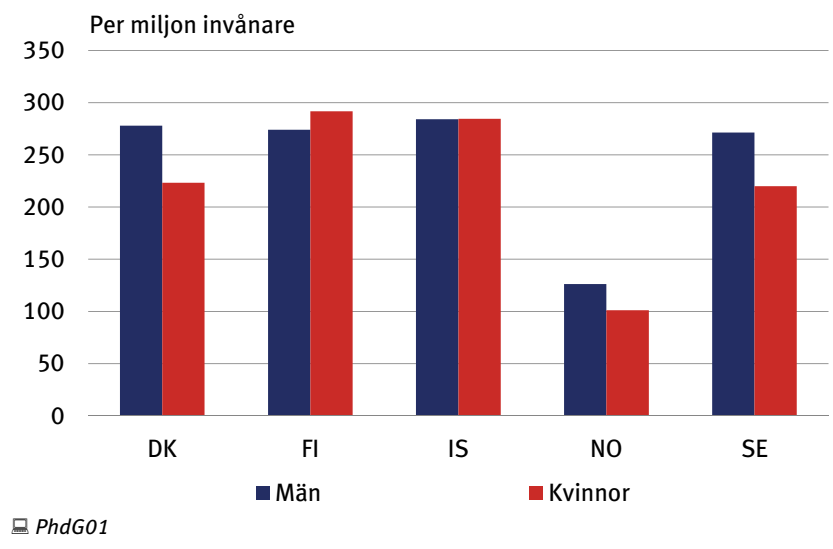

Köp via Internet av privatpersoner

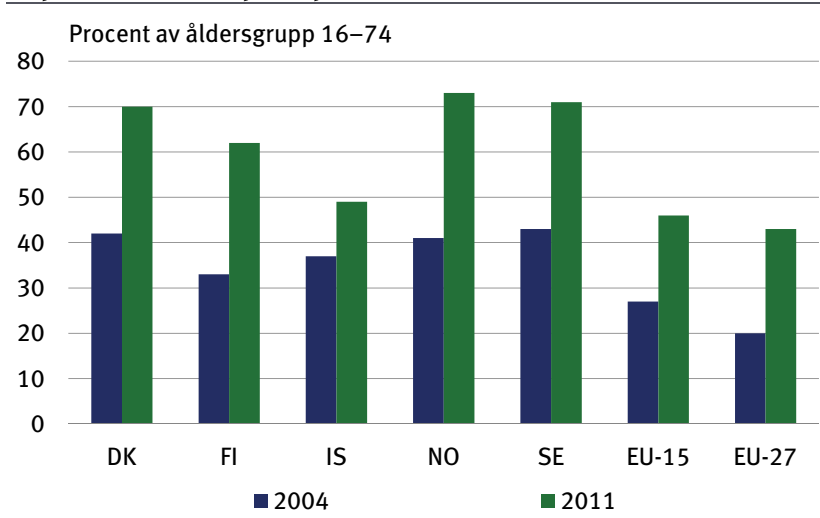

ㅇfo13 
Vetenskap och teknologi

Kommunikation mellan medborgare och myndigheter via Internet 2011

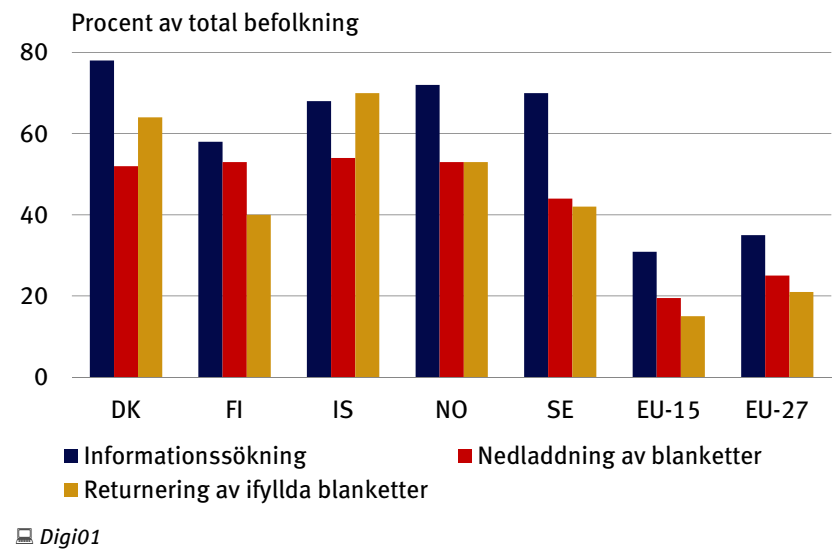

Kommunikation mellan företag och myndigheter via Internet 2011

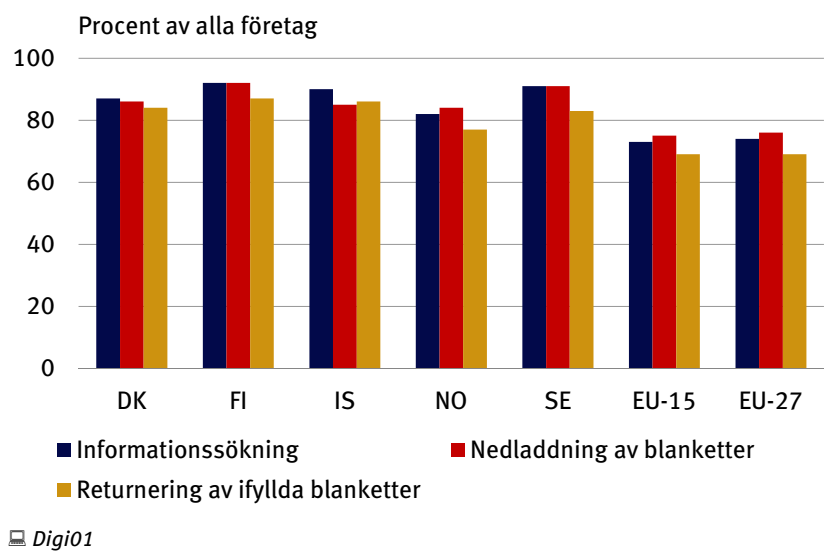

